\title{
Determinants of local ant (Hymenoptera: Formicidae) species richness and activity density across Europe
}

\author{
S A B R I N A K UM S C H I K , ${ }^{1}$ M AR T I N H. S C H M I D T - E N T L I N G, \\ SVEN B ACHER, ${ }^{2}$ T H O M A H I K LER, ${ }^{3}$ X A VIER ESPADALER ${ }^{4}$ and \\ W O L F G A N G N E N T W I G ${ }^{1}{ }^{1}$ Institute of Ecology and Evolution, University of Bern, Bern, Switzerland, \\ ${ }^{2}$ Department of Biology, Ecology \& Evolution Unit, University of Fribourg, Fribourg, Switzerland, ${ }^{3}$ Department of Physical \\ Geography \& Ecosystems Analysis, University of Lund, Lund, Sweden and ${ }^{4}$ Animal Biodiversity Group, Ecology Unit and \\ CREAF, Autonomous University of Barcelona, Bellaterra, Spain
}

\begin{abstract}
Species richness is influenced by local habitat features and large-scale climatic gradients. Usually, both influences are studied in isolation because of the divergent spatial scales at which they occur. Here, we compared the influence of large-scale climate and local habitat type on European ants using a continent-wide, standardised sampling programme.

2. We investigated species richness and activity density from pitfall traps distributed over four habitat types at 17 locations from northern Sweden to Spain and Greece. Species richness and activity density were analysed with respect to ambient energy [equilibrium evapotranspiration (EET)] and productive energy (net primary productivity). Furthermore, we compared ant richness and activity density between the four habitat types: arable land, scrubland, grassland, and forest.

3. Species richness and activity density of ants increased with equilibrium evapotranspiration (EET), explaining $30.2 \%$ of the total variation in species richness and $24.2 \%$ of activity density. Habitat type explained an additional $19.2 \%$ of the variation in species richness and $20.2 \%$ of activity density, and was not related to productivity. Species richness and activity density were highest in scrubland and significantly lower in forest and (marginally significant) in arable land.

4. The increase in EET and the decrease in forest confirms the pronounced thermophily of ants, whereas the decrease in arable land is probably caused by soil disturbance.
\end{abstract}

Key words. Ambient energy hypothesis, biodiversity, disturbance, diversity gradient, equilibrium evapotranspiration, habitat type, productivity hypothesis.

\section{Introduction}

On large spatial scales, species richness is largely determined by latitudinal gradients of climate (Willig et al., 2003; Clarke \& Gaston, 2006; Hawkins et al., 2007). Generally, species richness increases from the poles to the equator, respectively, from arctic to tropical climates. This applies to most taxonomic groups and to organisms occupying terrestrial, freshwater, and marine environments. Energy-related factors are proposed to be the reason for these species-richness patterns (e.g. Hawkins et al., 2003). In a still ongoing debate, many authors studied

Correspondence: Sabrina Kumschick, Institute of Ecology and Evolution, University of Bern, Baltzerstrasse 6, 3012 Bern, Switzerland. E-mail: sabrina.kumschick@iee.unibe.ch possible reasons for the link between energy and species richness in different taxonomic groups (Hawkins et al., 2003; Willig et al., 2003; Evans et al., 2005). They distinguish two potential mechanisms. First, the productivity hypothesis proposes that energy constrains richness via trophic cascades (Mittelbach et al., 2001). It states that higher population densities at high levels of primary productivity allow more species to coexist and therefore lead to higher species richness. Second, the ambient energy hypothesis is founded on metabolic and mutation rates rather than food availability (Allen et al., 2002). Still the mechanisms that determine species diversity might vary with spatial scale (Chase \& Leibold, 2002). On a local scale, productivity-diversity relations are often hump shaped, whereas on a regional scale they are linear. 
Most of the existing studies on large-scale patterns of biodiversity on invertebrates deal with atlas data (but see Kaspari et al., 2000). This kind of data source lacks information on densities, which are an integral part of suggested mechanisms such as the productivity hypothesis (see also Srivastava \& Lawton, 1998). Direct field sampling can provide such information. However, most field sampling studies were conducted over a relatively small spatial scale and field sampling studies on a large geographical extent on biodiversity are scarce.

Existing studies concerning ant species richness in northern Europe (e.g. Cushman et al., 1993) found a negative correlation between ants and latitude, therefore showing more ant species in the south and less towards the north. Previous studies on latitudinal gradients in species richness of ants in several regions of the world concluded that ants are more species rich in regions with higher energy input (e.g. Gotelli \& Ellison, 2002; Kaspari et al., 2004). Energy-related factors such as the number of hours of sunshine or temperature were proposed to play an important role in ant species richness patterns (Gotelli \& Ellison, 2002), but productivity may also be important (Kaspari et al., 2000).

An advantage of sampled field data is that it is habitat specific. Including field data in a study of biodiversity might be important as at a local scale, since species and individuals interact with different factors than at regional scale. At a local scale, ants have different requirements to their habitat such as nest site availability (Way \& Bolton, 1997). Furthermore, the structural complexity of the foraging surface has an influence on ant species (Kaspari \& Weiser, 1999) as well as disturbance of the soil (Robertson et al., 1994). Ants are also sensitive to plant cover and diversity (Morrison, 1998) and disturbance regime in general (Feener \& Schupp, 1998). For these reasons, we take local habitat samples to explore potential mechanisms behind continental diversity patterns.

In this study, we tested for two main hypotheses concerning the relation of species richness and activity density to energy. We compared the influence of productivity and ambient energy on species richness and activity density. Additionally, we compared richness and activity density of ants between the four habitat types sampled (forest, scrubland, grassland, arable land) to account for their requirements on a local scale.

According to the ambient energy hypothesis, we expect equilibrium evapotranspiration (EET) to be the most important driver of ant species richness. The productive energy hypothesis predicts net primary productivity (NPP) to explain gradients in activity density and species richness of European ants, and this relation might be hump shaped as we sampled data on a local scale. Furthermore, we hypothesise that ants decrease along the disturbance gradient from forest to scrubland to grassland to arable land.

\section{Material and Methods}

\section{Study organisms}

Ants (Hymenoptera, Formicidae) are common in terrestrial habitats worldwide, excluding Antarctica and some oceanic islands. With 12000 known species, they are a diverse insect family, but their contribution to biomass is even higher. Ants monopolise on average $15-20 \%$ of the entire terrestrial animal biomass, and in the tropics even $25 \%$ or more (Schultz, 2000). Ants play numerous roles in communities and ecosystems, acting as scavengers, predators and herbivores (Hölldobler \& Wilson, 1990).

\section{Data}

Ants were sampled at 17 field sites distributed over Europe (Fig. 1). Fourteen of the sites belong to the ALARM (www.alarmproject.net) field site network, which allowed us to conduct joint research over the whole continent. Three additional sites (Bern, Vienna, and Silkeborg) were chosen to fill geographic gaps. At each field site, two habitats were sampled, which consisted of arable land, grassland, scrubland or forest (Fig. 1). There are two exceptions from this setup: Abisko (Sweden) had only scrubland as a result of the absence of agriculture, and at the Lesbos (Greece) site, only grassland was available. These four habitat types represent a gradient in disturbance and succession age.

To standardise sampling, we mailed pitfall trap material, preservation liquid, and an instruction manual to the respective field site managers, who performed the trapping procedure. Trapping was carried out in 2006 and started 5 days after the average start of the growing season in Europe for the period 1961-1998 (Rötzer \& Chmielewski, 2001). This varied from late March in the Mediterranean part of Europe to June in the northernmost field site of Abisko. Pitfall traps were installed $20 \mathrm{~m}$ from the road or track by which the habitat was accessed. Eight traps were placed in a transect $3 \mathrm{~m}$ apart from each other. Plastic beakers of $7 \mathrm{~cm}$ diameter and $8 \mathrm{~cm}$ height were used as traps, and dug into the soil so that the upper borders of the traps were at the level of the soil surface. Traps were filled with $0.1 \mathrm{~L}$ of a $4 \%$ formaldehyde solution as a trapping liquid, to which a few drops of solved sodium dodecyl sulphate (SDS) were added as detergent. After 2 weeks of trap exposure, traps were emptied and closed for 2 weeks. This procedure was repeated three times. The contents of all traps were shipped back to Bern where arthropods were transferred into $75 \%$ ethanol.

Ants were identified using existing keys for Central and Northern Europe (Collingwood, 1979; Czechowski et al., 2002; Kutter, 1977; Seifert, 2007), the Iberian Peninsula (Collingwood, 1978), and the reference collection of European ants of one of the authors (XE). Species numbers and densities of ants were pooled over the entire sampling period and $\log _{10^{-}}$ transformed prior to the analysis.

Climatic variables were extracted from a European gridded data set with a monthly time step and high spatial resolution $(10 \times 10$ arc minute, which corresponds approximately with $16 \mathrm{~km}$ ) described by Mitchell et al. (2004). EET and NPP were estimated by running the LPJ-GUESS vegetation model (Smith et al., 2001) with the same climate data, and parameterised for representing the potential natural vegetation of Europe (Hickler et al., 2009). EET is a direct measure of the energy provided to the atmosphere through radiation (Jarvis \& McNaugthon, 


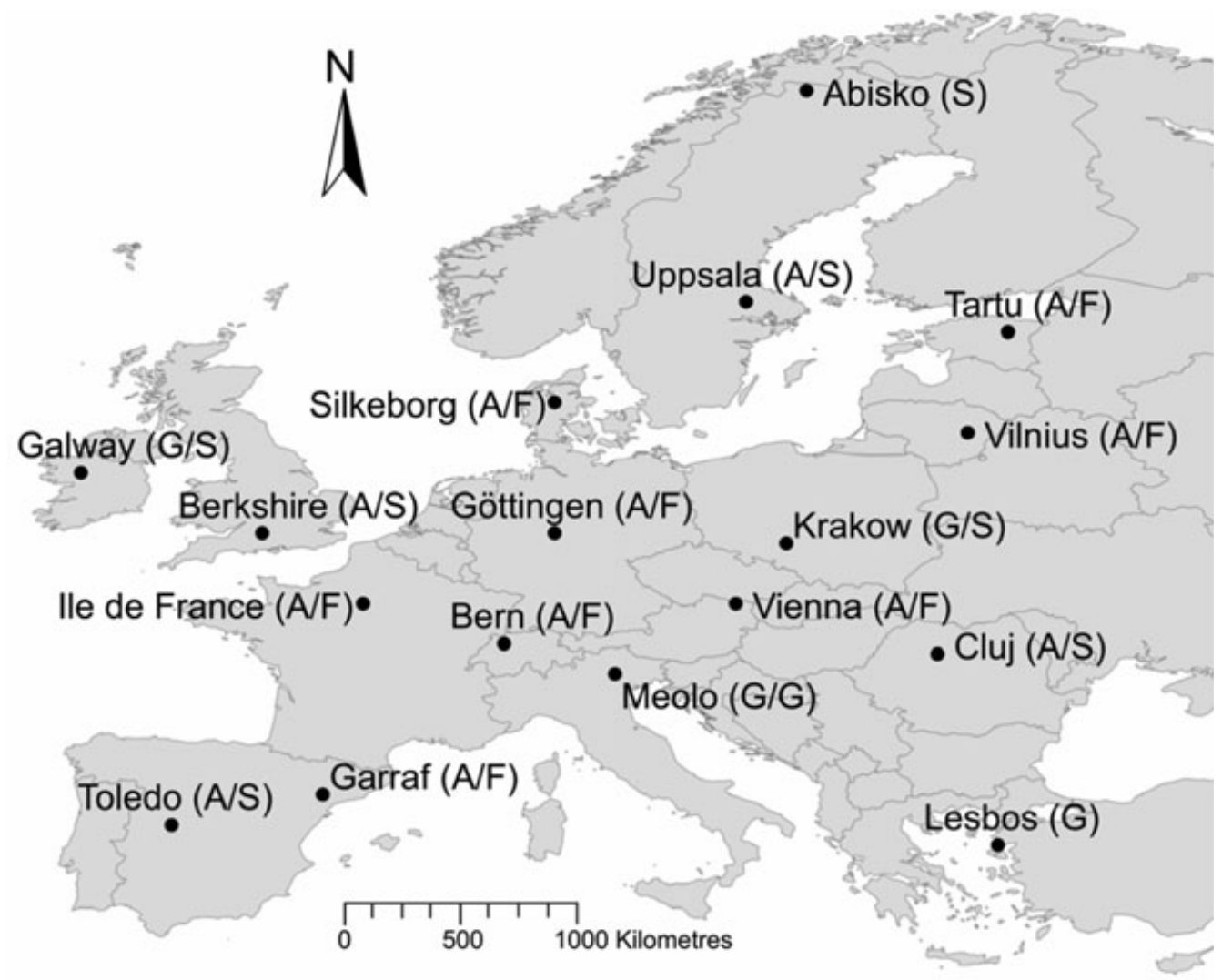

Fig. 1. Distribution of the sampling sites across Europe. The habitat type(s) sampled at each site are given in parentheses. F, forest; S, scrubland; $\mathrm{G}$, grassland; A, arable land.

1986). Estimating the potential evapotranspiration (PET), which is often used, is more complex as PET is also driven by water pressure gradients between the surface and the air masses above, which dynamically interact with the actual evapotranspiration (AET) and depend on the amount of water transported away from the surface by wind (Hobbins et al., 2001). On large scales (such as grid cells with several kilometre extent), PET can be estimated by multiplying EET with a constant of approximately 1.3 (Hobbins et al., 2001). For all variables, we used yearly totals, averaged for 1971-2000, to characterise the general conditions at the sites.

LPJ-GUESS is a process-based, dynamic vegetation model that simulates successional vegetation development and biogeochemical fluxes (Smith et al., 2001). Model representations of ecophysiologial processes, such as photosynthesis, respiration, and transpiration, are derived from those of the widely used Lund-Potsdam-Jena Dynamic Global Vegetation Model (LPJ-DGVM; Sitch et al. 2003). The approach for modelling tree population dynamics has been adopted from so-called forest 'gap models', in which establishment, growth, and mortality of tree individuals or cohorts, as well as disturbance events, are simulated for a number of replicate patches (approximately $1000 \mathrm{~m}^{2}$ ), the average of all simulations representing the regional vegetation (here a $10 \times 10$ arc minute grid cell; approximately $16 \times 16 \mathrm{~km}$ ). Model inputs consist of daily mean temperature, rainfall, radiation, atmospheric $\mathrm{CO}_{2}$ concentration, and soil texture. The model and its set-up for this study is fully described in Smith et al. (2001), Gerten et al. (2004) for hydrological updates, and Hickler et al. (2009). LPJGUESS and the closely related LPJ-DGVM (Sitch et al., 2003) have formerly been shown to reproduce observed variations in NPP and water cycling across various biomes (e.g. Gerten et al., 2004; Hickler et al., 2006).

\section{Analyses}

We checked for sample completeness (how much of all potential species we sampled) by dividing observed species richness by the abundance-based coverage estimator (a nonparametric estimator to estimate the potential number of species living at a given site) using the programme EstimateS (Colwell et al., 2004). As sample completeness was nearly $100 \%$ at most sites and similar between habitats (Supporting information Table S1 and S2), we used raw species richness in the following. Influences of climate on local species richness were tested using general linear models in $\mathrm{R}$ version 2.6.1 (R Development Core Team, 2007). Ant species richness and activity density was analysed with respect to the climatic variables EET and NPP, their quadratic response and habitat type. Furthermore, interactions between climatic variables and habitat type were tested. Afterwards, we carried out an ANOVA 
(error type II; according to the principle of marginality, testing each term after all others) of the reduced models with the $\mathrm{R}$ package car for estimating the overall effect of categorical variables with more than two levels. To correct for shortscale autocorrelation between the habitats per location, we additionally calculated the average species richness and density of the two habitats and repeated the analyses with just these 17 locations. To compare the influences of the different habitat types, we performed a Tukey HSD test on the residuals of species richness and activity density after accounting for EET. The residuals were used to only account for the variation in the data after correcting for the influence of climate.

\section{Results}

Productivity versus ambient energy

Species richness and activity density were best explained by models with habitat type and EET (Table 1, Fig. 2a,b; Figures with NPP, Supporting information Fig. S1) and there were no significant quadratic terms (not shown). These results are robust when testing average species richness and density with respect to EET in the 17 locations (Species richness: $P=0.03$; Density: $P=0.04)$. Species richness and activity density increased with increasing EET. EET explained $30.2 \%$ of the variance in species richness and $24.2 \%$ of activity density. Interactions between climatic variables and habitat type were not significant $(P>0.2)$.

\section{Habitats}

Habitat type significantly influenced species richness and activity density after accounting for EET (Table 1). Habitat type explained $19.2 \%$ of the variance in species richness and
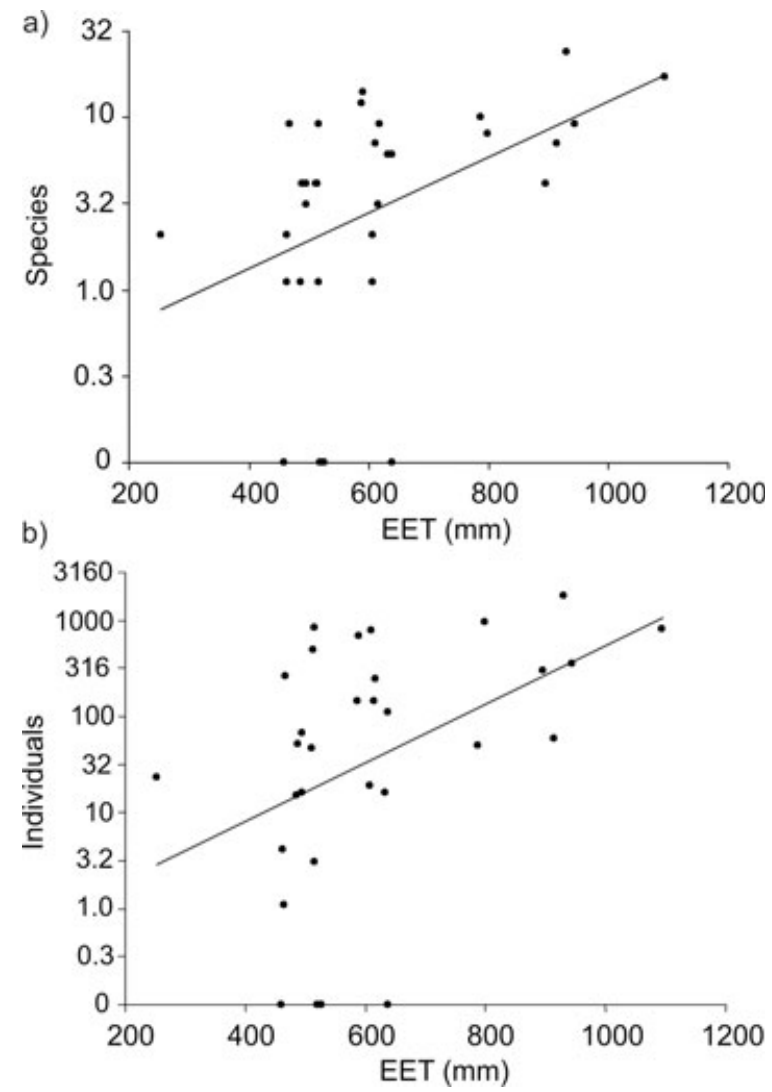

Fig. 2. Correlation of ant species richness (a) and individual density (b) with equilibrium evapotranspiration (EET). $y$-axis is shown as logscales, trendlines are shown over all field sites.

$20.2 \%$ in activity density of ants in Europe. Post hoc testing of the different habitat types in field sampling data showed that

Table 1. Comparison of general linear models explaining ant species richness and activity density with ambient energy [equilibrium evapotranspiration (EET)] versus productive energy (NPP). The models for species richness and activity density with overall lowest AIC values are written bold face.

\begin{tabular}{|c|c|c|c|c|c|c|c|}
\hline \multirow[b]{2}{*}{ Hypothesis } & \multirow[b]{2}{*}{ Variables } & \multicolumn{3}{|c|}{ Species } & \multicolumn{3}{|c|}{ Individuals } \\
\hline & & d.f. & $\mathrm{F}$ & $\mathrm{P}$ & d.f. & F & $\mathrm{P}$ \\
\hline \multirow{4}{*}{ Productivity } & NPP & 1 & 0.15 & 0.701 & 1 & 0.39 & 0.537 \\
\hline & Habitat & 3 & 2.03 & 0.133 & 3 & 2.43 & 0.087 \\
\hline & Residuals & 27 & & & 27 & & \\
\hline & \multicolumn{3}{|c|}{$\mathrm{AIC}=34.3$} & \multicolumn{3}{|c|}{$\mathrm{AIC}=93.6$} & \\
\hline \multirow{4}{*}{ Ambient energy } & EET & 1 & 16.13 & $<0.001$ & 1 & 11.76 & 0.002 \\
\hline & Habitat & 3 & 3.42 & 0.031 & 3 & 3.28 & 0.036 \\
\hline & Residuals & 27 & & & 27 & & \\
\hline & \multicolumn{3}{|c|}{$\mathrm{AIC}=19.5$} & \multicolumn{3}{|c|}{$\mathrm{AIC}=82.5$} & \\
\hline \multirow{5}{*}{$\begin{array}{l}\text { Productivity }+ \\
\text { ambient } \\
\text { energy }\end{array}$} & NPP & 1 & 0.01 & 0.930 & 1 & 0.16 & 0.694 \\
\hline & EET & 1 & 15.31 & $<0.001$ & 1 & 11.02 & 0.003 \\
\hline & Habitat & 3 & 3.09 & 0.045 & 3 & 3.16 & 0.042 \\
\hline & Residuals & 26 & & & 26 & & \\
\hline & \multicolumn{3}{|c|}{$\mathrm{AIC}=21.5$} & \multicolumn{3}{|c|}{$\mathrm{AIC}=84.3$} & \\
\hline
\end{tabular}




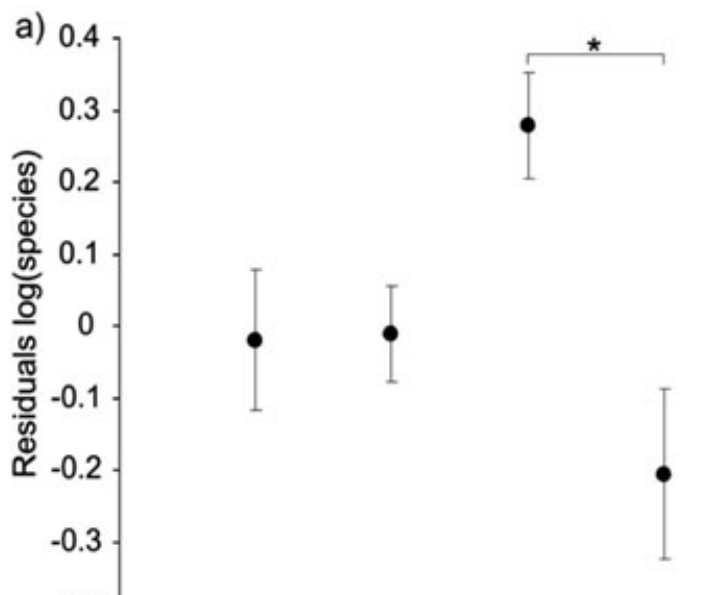

$\frac{c}{u}$
0
$\frac{0}{0}$
0
0
0
0
0

Arable land Grassland Scrubland Forest

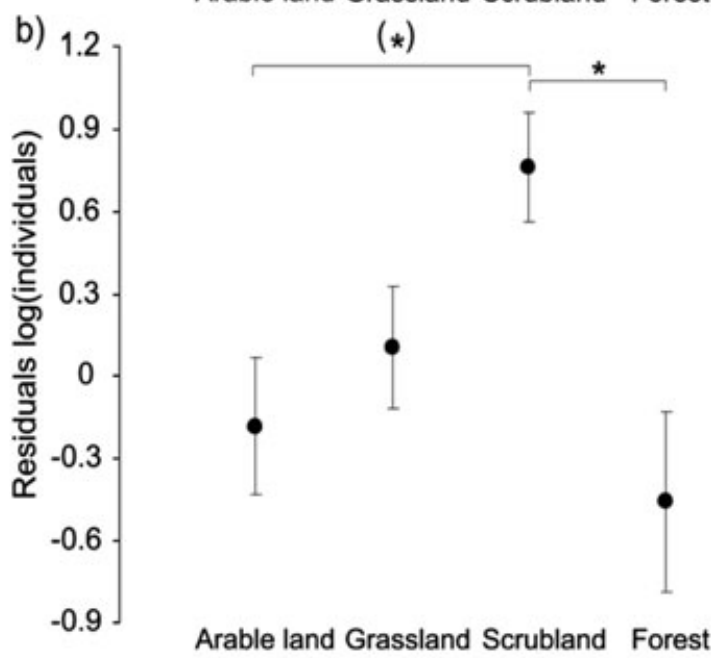

Fig. 3. Comparison of ant (a) species richness and (b) activity density between each pair of habitats. Residuals after accounting for equilibrium evapotranspiration (EET) are shown. Error bars are standard errors of the mean. Significant differences $(P<0.05)$ between habitats are marked with $*$, marginally significant $(0.1>P<0.05)$ ones with $(*)$.

species richness $(P=0.016)$ and activity density $(P=0.026)$ were significantly lower in forest than in scrubland (Fig. 3a,b). Furthermore, there was a trend towards lower activity density in arable land than scrubland $(P=0.075)$.

\section{Discussion}

\section{Productivity versus ambient energy}

Low levels of ambient energy are considered to be the primary stress controlling global patterns of ant productivity and community structure (Andersen, 1995). Our results confirm this, namely that more ants occur where energy is high. There are two explanations for this pattern. On the one hand, it is very likely that because of higher energy input, metabolic rate and therefore population density is increased in lower latitudes (Allen et al., 2002), leading to higher species richness. On the other hand, it is also possible that it is low energy in the north, which diminishes species richness because of limited cold resistance of many ant species. This might make the pattern even clearer. It is well known that temperature is a pre-eminent condition for ant populations. As a taxon ants are thermophilic, shutting down in winter and avoiding cold shade within the studied latitudes (Brian \& Brian, 1951). Thus, it is likely that there are fewer ant species which can survive cold temperature and that these are less active. Ants are constrained to forage when it is warm, but not too warm. This results in a temperature envelope in which most ants forage at temperatures higher than $10^{\circ} \mathrm{C}$ and cease foraging much above $40^{\circ} \mathrm{C}$, with an average peak foraging temperature of $30^{\circ} \mathrm{C}$ (Hölldobler \& Wilson, 1990). In the northern sampling locations of this study, the average temperature was around $0-6^{\circ} \mathrm{C}$, and this is too cold for many ant species.

Overall, ant species richness and density is positively correlated with EET in Europe. In contrast, Kaspari et al. (2000) found that net aboveground productivity (NAP) is the best predictor of local ant densities between $44^{\circ} \mathrm{N}$ and $0^{\circ} \mathrm{N}$ in the Western Hemisphere. However, Kaspari et al. (2000) used AET as a surrogate for NAP, and AET was modelled from mean monthly temperature and rainfall data, vegetation type and latitude. AET is generally highly correlated with NAP, but such a coarse approach does not necessarily reflect NAP at each site. The predominant role of productive energy in Kaspari et al. (2000) and of ambient energy in the current study might also be explained by the different range of climates and habitat types studied. At the habitat level, productivity and resulting food availability is most likely to be limited in hot and dry habitats such as the desert (Marsh, 1986). While Kaspari et al. (2000) included deserts in their analysis, the habitats that we investigated may all provide sufficient amounts of food for high levels of ant diversity and density. In contrast, ants may be unable to exploit even abundant food resources when levels of ambient energy are too low for workers to be active (Hölldobler \& Wilson, 1990). This may be important mostly at high latitudes above $45^{\circ} \mathrm{N}$, which comprise the majority of our sampling sites but not in the study of Kaspari et al. (2000). Notably, Hawkins et al. (2003) found a latitudinal shift from ambient to productive energy to be driving species richness patterns. Ambient energy seems to limit species richness mostly at high latitudes, whereas productive energy governs the picture from the Mediterranean to the tropics. Kerr and Packer (1997) found that for North American mammals this shift takes place at around $45-48^{\circ} \mathrm{N}$, and similar latitudes were found for other taxa (Hawkins et al., 2003).

Estimating NPP in the field is very demanding, because some important components are difficult to measure (e.g. root exudates and fine root turnover). Even measurements of ambient energy are rarely available for sites with species richness or diversity estimates. Therefore, most studies covering a number of sites over large environmental gradients rely on modelled proxies for ambient and productive energy, often based upon coarse-scale or nearby weather station climate data. This 
applies also to our study, but the climate data used for estimating energy has a relatively fine scale (about $16 \mathrm{~km}$ ) and we use modelled NPP instead of proxies such as AET, making us confident that the presented relationships reflect real-world processes.

Despite the clear correlation of ant richness and density with ambient energy, there is possibly another, historical explanation for this pattern. There might be time-lags in post-glacial recovery of ant species range distributions across Europe. For example, for European trees it has been found that postglacial dispersal limitation might be a strong determinant of current tree diversity and distribution patterns (Svenning \& Skov, 2007). This might to a certain extent also apply to ants, as they are also limited in dispersal. Still, in many cases it is not possible to separate contemporary explanations from historical ones and therefore, we concentrate on contemporary climatic explanations in this study.

\section{Habitats}

From an ant perspective, temperature is a product of both climate (which controls ambient temperature) and habitat structure (which determines the degree of insolation of the foraging surface and therefore microclimate). Low-temperature stress is high in cool and shaded habitats, moderate in cool and open or warm and shaded habitats, and low in warm and open habitats (Andersen, 1995). This explains why ant richness was comparatively low in the forest, despite its low level of habitat disturbance.

The availability of nest sites (the range of types and their abundance) exerts an important influence on ant productivity and community structure. The range of types of nest sites varies with the structural complexity of the habitat, and this range constrains the types of ants that can occur there (Armbrecht et al., 2004). Furthermore, complexity of the foraging surface exerts a major influence on the ability of ant species to capture food resources (size-grain hypothesis; Farji-Brener et al., 2004). For example, leaf litter on the ground reduces the efficiency with which resources can be located, retrieved, and defended by epigeic ants. This factor has a major effect on ant community structure and possibly also influences overall ant productivity. This provides an additional explanation why ant richness was comparatively low in the forests.

We expected that habitat disturbance would reduce ant species richness and activity density. This expectation was only confirmed regarding a slight decrease in activity density in arable land. A limitation of disturbance effects to arable land may be a result of the dominant importance of soil disturbance, which affects ants through the disruption of nests (Peck et al., 1998). Having controlled for regional climate, species richness and activity density of ants is highest in scrubland in Europe.

\section{Conclusion}

For the first time, we have quantified the relative importance of large-scale climatic gradients, productivity, and habitat type as drivers of ant biodiversity in Europe. Habitat type and large-scale climate influence ant species richness and activity density to a similar extent, but available energy is probably the main driver as it also correlates with habitat types. However, our results also suggest an important role for the disturbance of habitats.

\section{Acknowledgements}

We especially thank Monica Wyss-Lopez for logistic support. The traps were operated by Monica Wyss-Lopez, Joan Pino, Ivan Torres, Sara Bonzini, Catrin Westphal, Simon Potts, Dawid Moron, Riccardo Bommarco, Mari Moora, Eduardas Budrys, Jane Stout, Laszlo Rakosy, Steen Hansen, Thomas Frank, Agnès Rortais, Torben Christensen and Michael Greenwell. The ALARM Field Site Network was coordinated by Koos Biesmeijer and Bill Kunin. Timothy D. Mitchell from the Climatic Research Unit, University of East Anglia, provided the CRU 2.1 gridded climate data set. FSN is funded by the EC within the FP 6 Integrated Project ALARM (Assessing LArge scale environmental Risks for biodiversity with tested Methods; GOCE-CT-2003-506675; www.alarmproject.net).

\section{Supporting Information}

Fig. S1. Correlation of ant species richness (a) and individual density (b) with NPP. Y-axes are shown as log-scales, trendlines are shown over all field sites.

Table S1. Coverage in \% per site and habitat type. Coverage is calculated as number of species sampled divided by the abundance based coverage estimator (ACE). Missing values represent sites where no ants have been sampled.

Table S2. Comparison of coverage between the four habitat types with Tukey HSD test. 'Difference' giving the difference in the observed means, 'Lower' giving the lower end point of the interval, 'Upper' giving the upper end point. P-values are given after adjustment for the multiple comparisons.

Please note: Wiley-Blackwell are not responsible for the content or functionality of any supporting materials supplied by the authors. Any queries (other than missing material) should be directed to the corresponding author for the article.

\section{References}

Allen, A.P., Brown, J.H. \& Gillooly, J.F. (2002) Global biodiversity, biochemical kinetics, and the energetic-equivalence rule. Science, 297, 1545-1548.

Andersen, A.N. (1995) A classification of Australian ant communities, based on functional groups which parallel plant life forms in relation to stress and disturbance. Journal of Biogeography, 20, 15-29.

Armbrecht, I., Perfecto, I. \& Vandermeer, J. (2004) Enigmatic biodiversity correlations: Ant diversity responds to diverse resources. Science, 304, 284-286.

Brian, M.V. \& Brian, A.D. (1951) Insolation and ant populations in the west of Scotland. Transactions of the Royal Entomological Society of London, 102, 303-330. 
Chase, J.M. \& Leibold, M.A. (2002) Spatial scale dictates the productivity-biodiversity relationship. Nature, 416, 427-430.

Clarke, A. \& Gaston, K.J. (2006) Climate, energy and diversity. Proceedings of the Royal Society, 273, 2257-2266.

Collingwood, C.A. (1978) A provisional list of Iberian Formicidae with a key to the worker caste (Hym. Aculeata). EOS - Revista Española de Entomologia, 52, 65-95.

Collingwood, C.A. (1979) The Formicidae (Hymenoptera) of Fennoscandia and Denmark. Fauna Entomologica Scandinavica, 8, 1-174.

Colwell, R.K., Mao, C.X. \& Chang, J. (2004) Interpolating, extrapolating, and comparing incidence-based species accumulation curves. Ecology, 85, 2717-2727.

Cushman, J.H., Lawton, J.H. \& Manly, B.F.J. (1993) Latitudinal patterns in European ant assemblages: variation in species richness and body size. Oecologia, 95, 30-37.

Czechowski, W., Radchenko, A. \& Czechowska, W. (2002) The ants (Hymenoptera: Formicidae) of Poland. Museum and Institute of Zoology PAS, Warsaw, Poland.

Evans, K.L., Warren, P.H. \& Gaston, K.J. (2005) Species-energy relationships at the macroecological scale: a review of the mechanisms. Biological Reviews, 80, 1-25.

Farji-Brener, A.G., Barrantes, G. \& Ruggiero, A. (2004) Environmental rugosity, body size and access to food: a test of the size-grain hypothesis in tropical litter ants. Oikos, 104, 165-171.

Feener, D.H. Jr \& Schupp, E.W. (1998) Effects of treefall gaps on the patchiness and species richness of Neotropical ant assemblages. Oecologia, 116, 191-201.

Gerten, D., Schabhoff, S., Haberlandt, U., Lucht, W. \& Sitch, S. (2004) Terrestrial vegetation and water balance - hydrological evaluation of a dynamic global vegetation model. Journal of Hydrology, 286, 249-270.

Gotelli, N.J. \& Ellison, A.M. (2002) Biogeopraphy at a regional scale: determinants of ant species density in New England bogs and forests. Ecology, 83, 1604-1609.

Hawkins, B.A., Field, R., Cornell, H.V., Currie, D.J., Guégan, J.F., Kaufman, D.M. et al. (2003) Energy, water, and broad-scale geographic patterns of species richness. Ecology, 84, 3105-3117.

Hawkins, B.A., Albuquerque, F.S., Araújo, M.B., Beck, J., Bini, L.M., Cabrero-Sañudo, F. et al. (2007) A global evaluation of metabolic theory as an explanation for terrestrial species richness gradients. Ecology, 88, 1877-1888.

Hickler, T., Prentice, I.C., Smith, B., Sykes, M.T. \& Zaehle, S. (2006) Implementing plant hydraulic architecture within the LPJ Dynamic Global Vegetation Model. Global Ecology and Biogeography, 15, 567-577.

Hickler, T., Fronzek, S., Araújo, M.B., Schweiger, O., Thuiller, W. \& Sykes, M.T. (2009) An ecosystem-model-based estimate of changes in water availability differs from water proxies that are commonly used in species distribution models. Global Ecology and Biogeography, 18, 304-313.

Hobbins, M.T., Ramírez, J.A. \& Brown, T.C. (2001) The complementary relationship in estimation of regional evapotranspiration: an enhanced advection-aridity model. Water Resources Research, 37, $1389-1403$.

Hölldobler, B. \& Wilson, E.O. (1990) The Ants. The Belknap Press of Harvard University Press, Cambridge, Massachusetts.

Jarvis, P.G. \& McNaugthon, K.G. (1986) Stomatal control of transpiration: scaling up from leaf to region. Advances in Ecological Research, 15, 1-45.

Kaspari, M. \& Weiser, M.D. (1999) The size-grain hypothesis and interspecific scaling in ants. Functional Ecology, 13, 530-538.

Kaspari, M., O'Donnell, S. \& Kercher, J.R. (2000) Energy, density, and constraints to species richness: ant assemblages along a productivity gradient. The American Naturalist, 155, 280-293.
Kaspari, M., Ward, P.S. \& Yuan, M. (2004) Energy gradients and the geographic distribution of local ant diversity. Oecologia, 140, 407-413.

Kerr, J.T. \& Packer, L. (1997) Habitat heterogeneity as a determinant of mammal species richness in high-energy regions. Nature, $\mathbf{3 8 5}$, 252-254.

Kutter, H. (1977) Hymenoptera, Formicidae. Insecta Helvetica: Fauna, Vol 6, pp. 1-298. Schweizerische Entomologische Gesellschaft, Zürich, Switzerland.

Marsh, A.C. (1986) Ant species richness along a climatic gradient in the Namibi Desert. Journal of Arid Environments, 11, 235-241.

Mitchell, T.D., Carter, T.R., Jones, P.D., Hulme, M. \& New, M. (2004) A Comprehensive Set of High-resolution Grids of Monthly Climate for Europe and the Globe: The Observed Record (19012000) and 16 Scenarios (2001-2100). Tyndall Center working paper 55 [WWW document]. URL http://www.tyndall.ac.uk/publications/ working_papers/wp55_summary.shtml. p. 25. [accessed January 2008].

Mittelbach, G.G., $\quad$ Steiner, C.F., $\quad$ Scheiner, S.M., $\quad$ Gross, K.L., Reynolds, H.L., Waide, R.B. et al. (2001) What is the observed relationship between species richness and productivity? Ecology, 82, 2381-2396.

Morrison, L.W. (1998) The spatiotemporal dynamics of insular ant metapopulations. Ecology, 79, 1135-1146.

Peck, S.L., McQuaid, B. \& Campbell, C.L. (1998) Using ant species (Hymenoptera: Formicidae) as a biological indicator of agroecosystem condition. Environmental Entomology, 27, 1102-1110.

R Development Core Team (2007) A Language and Environment for Statistical Computing. R Foundation for Statistical Computing, Vienna, Austria.

Robertson, L.N., Kettle, B.A. \& Simpson, G.B. (1994) The influence of tillage practices on soil macrofauna in a semi-arid agroecosystem in northeastern Australia. Agriculture, Ecosystems and Environment, 48, 149-156.

Rötzer, T. \& Chmielewski, F.-M. (2001) Phenological maps of Europe. Climate Research, 18, 249-257.

Schultz, T.R. (2000) In search of ant ancestors. Proceedings of the National Academy of Sciences, 97, 14028-14029.

Seifert, B. (2007) Die Ameisen Mittel- und Nordeuropas. Lutra Verlag, Tauer, Germany.

Sitch, S., Smith, B., Prentice, I.C., Arneth, A., Bondeau, A., Cramer, W. et al. (2003) Evaluation of ecosystem dynamics, plant geography and terrestrial carbon cycling in the LPJ Dynamic Global Vegetation Model. Global Change Biology, 9, 161-185.

Smith, B., Prentice, I.C. \& Sykes, M.T. (2001) Representation of vegetation dynamics in the modelling of terrestrial ecosystems: comparing two contrasting approaches within European climate space. Global Ecology and Biogeography, 10, 621-637.

Srivastava, D.S. \& Lawton, J.H. (1998) Why more productive sites have more species: an experimental test of theory using tree-hole communities. The American Naturalist, 152, 510-529.

Svenning, J.C. \& Skov, F. (2007) Could the tree diversity pattern in Europe be generated by postglacial dispersal limitation? Ecology Letters, 10, 453-460.

Way, M.J. \& Bolton, B. (1997) Competition between ants for coconut palm nesting sites. Journal of Natural History, 31, 439-455.

Willig, M.R., Kaufman, D.M. \& Stevens, R.D. (2003) Latitudinal gradients of biodiversity: pattern, process, scale, and synthesis. Annual Review of Ecology, Evolution, and Systematics, 34, 273-309. 